\title{
Comparative study of total dose infusion of iron and intramuscular iron administration in treatment of severe iron deficiency anemia during pregnancy
}

\author{
${ }^{1}$ Fahd Abd El Aal Al Omda, ${ }^{2}$ Abd El Raaof Abd El Raaof Abo Nar, ${ }^{1}$ Waleed El Sayed Al \\ Naggar, ${ }^{1}$ Mohamed Abdullah Al Sayed Al-Morsi \\ ${ }^{1}$ Department of Obstetrics and Gynecology, ${ }^{2}$ Department of Clinical Pathology, Faculty of Medicine- \\ Al-Azhar University
}

Corresponding author: Mohamed Abdullah Al Sayed Al-Morsi, Mobile: 01013354222, email: mhmdnmtallh165@gmail.com

\begin{abstract}
Background: Iron deficiency anemia is the most common type of anemia among pregnant women, especially in developing countries. Indeed, a majority of women in the reproductive age group in the developing countries are anemic even before conception; pregnancy only tends to intensify it further.

Objective: to compare the effectiveness and safety of intramuscular and intravenous iron therapy in pregnant women with severe iron deficiency anemia.

Patients and Methods: This study is an interventional randomized study, comparing the effect of intravenous and intramuscular iron therapy on pregnant women with severe anemia. Allocation of patients in either group (I.V \& I.M) was sealed and enveloped. The study was conducted at the Department of Obstetrics and Gynecology of General Helwan Hospital.

Results: The results of our study proved that the intravenous iron, showed high effectiveness in the treatment of iron deficiency anemia during pregnancy. Nearly no side effects were detected and thus, it can be considered as a useful and alternative formulation for the treatment of iron deficiency.

Conclusion: The present study proved that the severity of iron deficiency anemia affects the maternal outcome by increasing the risk of postpartum hemorrhage and also affects the fetal outcome by increasing the risk of preterm delivery and low birth weight.
\end{abstract}

Keywords: Adenosine triphosphate, Complete blood count, Hemoglobin

\section{INTRODUCTION}

Anemia is a very common condition in pregnancy affecting up to $32 \%$ of all pregnant women worldwide ${ }^{(\mathbf{1})}$.

Hemoglobin levels of less than $11 \mathrm{~g} / \mathrm{dL}$ at any time during pregnancy are considered abnormal $^{(2)}$.

Anemia is defined as hemoglobin $(\mathrm{Hb})$ less than $11 \mathrm{~g} / \mathrm{dl}$ in the first trimester, as well as $10.5 \mathrm{~g} / \mathrm{dl}$ in the second and third trimesters, according to current UK guidelines ${ }^{(\mathbf{3})}$.

Anemic pregnant women may present with fatigue, weakness, pallor, tachycardia, and shortness of breath, and are at higher risk of adverse perinatal outcomes such as low birth weight and preterm birth ${ }^{(4)}$.

Typical features of iron deficiency anemia are caused by lowered oxygen delivery to the tissues, and include pallor, fatigue, apathy, fainting, and breathlessness. Additional features include headache, palpitation, hair loss, and tinnitus. Chronic iron deficiency anemia lowers work tolerance, productivity, and the quality of life. This leads to further socioeconomic difficulties. Dysfunction in the immune system results in increased risks for infections ${ }^{(5)}$.

Anemia during pregnancy is associated with a number of maternal and fetal disorders including the risks of preterm births, low birth weight babies, perinatal mortality and intrauterine growth retardation ${ }^{(6)}$.

They also have an elevated risk of developing perinatal infection, pre-eclampsia, and bleeding. Post-partum cognitive impairment and behavioral difficulties were also reported ${ }^{(7)}$.

Iron deficiency during the first trimester, has a more negative impact on fetal growth than anemia developing later in pregnancy. This is also true for risk of preterm labor ${ }^{(\mathbf{8})}$. 
Over the past years, various routine methods like oral iron therapy, intramuscular iron therapy, and blood transfusion were used to treat anemia during pregnancy ${ }^{(9)}$. These methods are not without deficiencies, and also there are conditions in which these conventional iron therapies are not helpful, like inadequate gastrointestinal absorption, late pregnancy, intolerance to required oral iron, requirement of emergency supplement, and severe anemia with contraindications to blood transfusion. So, to treat these conditions, we require a relatively new mode of iron therapy with better efficacy, less side effects, fast action, and better compliance. Intravenous iron therapy seems to be a safe, convenient, and more effective treatment for severe anemia during pregnancy ${ }^{(\mathbf{1 0})}$.

\section{AIM OF THE WORK}

The aim of this study is to compare the effectiveness and safety of total dose infusion to intermittent intramuscular administration of iron therapy in pregnant women with severe iron deficiency anemia.

\section{Patients and Methods}

This study is an interventional randomized study, comparing the effect of intravenous and intramuscular iron therapy on pregnant women with severe anemia. Allocation of patients in either group (I.V \& I.M) was sealed and enveloped.

The study was conducted at the Department of Obstetrics and Gynecology of General Helwan Hospital.

The study consisted of 200 patients, divided into two groups: Group A: 100 patients for administration of total dose infusion of Iron. Group B: 100 patients for administration of intermittent intramuscular iron therapy.

Iron deficiency anemia patients were diagnosed by: $\mathrm{Hb} \leq 7 \mathrm{~g} / \mathrm{dL} . \mathrm{MCV}<60 \mathrm{fL}$. Serum ferritin $<20-30$ ug /L. Microcytic hypochromic picture on peripheral smear.

All patients included in this study were fulfilling these criteria:

Inclusion criteria: This study included 200 pregnant women in the $2^{\text {nd }}$ trimester of pregnancy with iron deficiency anemia who fulfilled the following eligibility criteria: 1 . Pregnant women with gestational age above 12 weeks and less than 36 weeks. 2. Hemoglobin less than $7 \mathrm{~g} / \mathrm{dl}$. 3. Patients were either intolerant (nausea, vomiting, abdominal and epigastric pain, dyspepsia, diarrhea, and/or constipation) or non compliant with oral iron supplementation. 4. Pregnant women aged more than 18 years. 5. Willingness to participate and signing the informed consent form.

Exclusion criteria: Subjects were not eligible for inclusion in this study if they fulfilled any of the following criteria based on history, examination and available investigations: 1. Anemia predominantly caused by factors other than iron deficiency anemia (e.g. anemia with untreated B12 or folate deficiency, hemolytic anemia) 2. Iron overload or disturbances in utilization of iron (e.g. hemochromatosis and hemosiderosis) 3 . Decompensated liver cirrhosis and active hepatitis (ALAT more than 3 times upper limit of normal). 4. Active acute or chronic infections (assessed by clinical judgement supplied with white blood cells (WBC) and C-reactive protein (CRP) 5. Rheumatoid arthritis with symptoms or signs of active inflammation. 6. History of multiple allergies or GIT disease. 7. Known hypersensitivity to parenteral iron or any recipients in the investigational drug products. 8. Erythropoietin treatment within 8 weeks prior to the screening visit. 9. Planned elective surgery during the study. 10. Multifetal pregnancy or multiple pregnancy. 11. Patient had medical or surgical disorders, which affect the level of hemoglobin including: (Fever, infection, diabetes mellitus, liver disorder, renal disease, tuberculosis, cardiovascular disease, gastrointestinal symptoms/disease, blood disease).

\section{Ethical and legal aspects:}

Good Clinical Practice: After reading the informed consent document, the patient was given written consent. The consent was confirmed by the personally dated signature of the patient and by the personally dated signature of the person conducting the informed consent discussions. The patient who was unable to read, oral consent was taken in the presence of an impartial witness or by a local legally recognized alternative (the thumbprint). The original signed consent document was retained by the investigator. The investigator did not undertake any measures specifically required only for the clinical study until valid consent was obtained. The study was 
approved by the Ethics Board of Al-Azhar University.

Confidentiality: Only the patient number and patient initials was recorded in the case record form (CRF). The investigator maintained a personal patient identification list (patient numbers with the corresponding patient names) to enable records to be identified.

Patient Information and Informed

Consent: Before being admitted to the clinical study, the patient was consent to participate after the nature, scope, and possible consequences of the clinical study had been explained in a form understandable to her. An informed consent document, in Arabic language, contains all locally corresponding documents was declared for Ethical and Research approval by the Council of OB/GYN Department, General Helwan Hospital.

\section{Laboratory Investigations:}

Kits used: Iron status assessment for each patient was assessed using biochemical tests including estimation of iron (micro $\mathrm{g} / \mathrm{dl}$ ) and TIBC (micro $\mathrm{g} / \mathrm{dl}$ ) using colorimetric kit (Stanbio laboratory, Boerne, TX USA) and ferritin (ng/ml) using ELISA (Diagnostic automation, INC cat \# 160 IZ).

Patient classification and administration: Using (cell dyn 1800) device, venous blood sample was drawn after randomization for: a. Complete blood count $(\mathrm{CBC})$. b. Serum Ferritin.

Group A: included 100 pregnant women who received intravenous full correction with total dose intravenous infusion of iron dextran. The drug that used was (cosmofer $50 \mathrm{mg} / \mathrm{ml}$ ). Each $2 \mathrm{ml}$ ampoule of cosmofer contains $100 \mathrm{mg}$ elemental iron as Iron Dextran. It is manufactured by Pharmacosmos A/S Roervangsve 30, DK4300 Holbaek Denmark. I.V group patients were admitted as day cases. Total dose infusion of iron dextran in single dose was calculated from the formula, (weight in $\mathrm{kg} \mathrm{x}$ hemoglobin deficient $\mathrm{x}$ $0.024+500 \mathrm{mg}$ ), where hemoglobin deficient = target hemoglobin-actual hemoglobin. Initially, test dose $(0.1 \mathrm{ml}$ diluted in $20 \mathrm{cc}$ of normal saline intravenous over a period of 20 minutes) was administered. Using small catheter (20 gauges) into a vein of sufficient caliber by slow, iron dextran was diluted in $500 \mathrm{ml} \mathrm{5 \%}$ dextrose and infused at a steady rate of $40 \mathrm{drops} / \mathrm{min}^{(11)}$. Antishock measures were prepared beside the patient during administration, (corticosterone, antihistamines and calcium) ${ }^{(12)}$. Patient was observed for any side effect for one hour and subsequently the entire dose diluted in 5\% dextrose saline was infused over a period of 6 hours. Adverse effect after infusion was identified by observation, direct inquiry and physical examination of each patient. Patient was seen after a week and was enquired for any delayed side effect like myalgia, arthralgia and gastric problems.

Group B: included 100 pregnant women who received intermittent intramuscular iron administration of ferric hydroxide polymaltose complex. The drug that used was heamojet $(50 \mathrm{mg} / \mathrm{ml})$. Each $2 \mathrm{ml}$ ampoule of heamojet contains $100 \mathrm{mg}$ elemental iron as ferric hydroxide polymaltose complex. It is manufactured by Pharco B International for European Egyptian Pharmaceutical Industries. Total iron requirement in intramuscular administration was calculated by the formula $(0.3 \times \mathrm{W} \times \mathrm{D}+$ $500 \mathrm{mg}$ ); where $\mathrm{W}$ is the weight of patient in $\mathrm{kg}, \mathrm{D}$ is deficiency in hemoglobin percentage (target $\mathrm{Hb}$ - actual $\mathrm{Hb}$ ), and $500 \mathrm{mg}$ is the iron for replenishing stores. The so obtained iron requirement was divided into nearly equal 4 fractions to be given in the form of 4 injections of iron ferric hydroxide polymaltose complex $(50 \mathrm{mg} / \mathrm{ml})$ at weekly intervals for 4 weeks.

The injection was given deeply intramuscularly in buttocks by z- track technique (13).

This technique involved displacing the skin laterally before injection, inserting a 2-3 inch needle deep into muscle tissue and injecting the medication followed by a small amount of air and waiting approximately 10 seconds before withdrawing the needle.

Follow up: Repeating $\mathrm{Hb}$ and serum ferritin 4 weeks after last dose of therapy. The hemoglobin concentration should rise by approximately $20 \mathrm{~g} / \mathrm{l}$ over 3-4 weeks ${ }^{(14)}$. Follow up of patients at time of delivery was done to evaluate maternal outcome (mode of delivery, post partum hemorrhage and lactation) and fetal outcome (gestational age at time of delivery, weight and Apgar score).

\section{Outcome measures:}

Primary main issue: Comparing the effect of intravenous and intermittent intramuscular iron therapy on severe anemic pregnant patients and how the outcome was (maternal and fetal). 
Secondary other findings: Maternal side effects as myalgia, anaphylactic reaction and local thrombophlebitis.

\section{Statistical analysis:}

Comparison between numerical data in the two studied groups was performed using unpaired $\mathrm{t}$ test; while comparison between before and after iron intake within the same group was performed using paired $\mathrm{t}$ test. Comparison between categorical data was performed using Chi square test. SPSS computer program (version 19 windows) was used for data analysis.

Data were statistically described in terms of mean \pm standard deviation $( \pm \mathrm{SD})$ or number $(\%)$.

For comparison between both groups, a difference in variables was expressed by $\mathrm{P}$ value $(<0.05$ is significant, $>0.05$ is non significant, and $<0.01$ is highly significant).

\section{RESULTS}

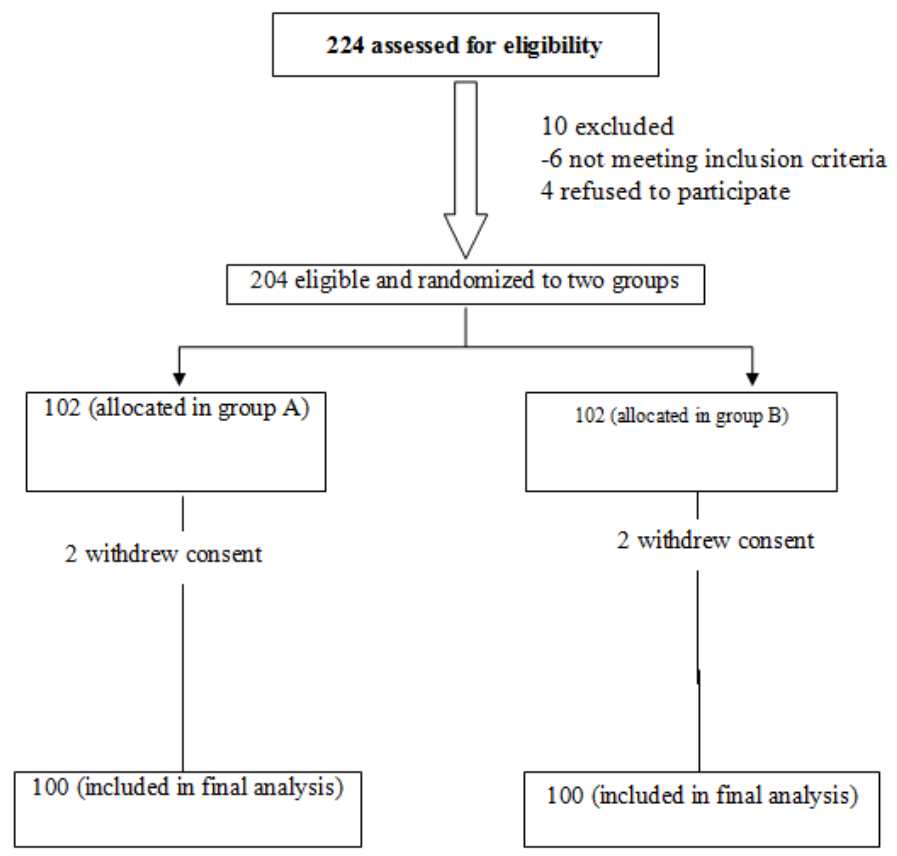

Fig. (1): Flow-Chart showing patient's progress through the randomized study.

Table (1): Comparison between the two groups as regard Apgar score (1 min. / 5 min.)

\begin{tabular}{|c|c|c|c|c|c|c|c|c|}
\hline \multirow{2}{*}{ Apgar score } & \multicolumn{3}{|c|}{ Group A } & \multicolumn{3}{c|}{ Group B } & \multicolumn{2}{c|}{ T-test } \\
\cline { 2 - 9 } & Mean & \pm & SD & Mean & \pm & SD & T & P-value \\
\hline At 1 min. & 6.80 & \pm & 0.83 & 6.61 & \pm & 0.83 & 1.622 & 0.106 \\
\hline At 5 min. & 8.00 & \pm & 0.91 & 7.85 & \pm & 0.95 & 1.142 & 0.255 \\
\hline
\end{tabular}

Table (2): Comparison between the two groups as regard parity

\begin{tabular}{|c|c|c|c|c|c|c|c|}
\hline \multirow{2}{*}{\multicolumn{2}{|c|}{ Parity }} & \multicolumn{2}{|c|}{ Group A } & \multicolumn{2}{|c|}{ Group B } & \multicolumn{2}{|c|}{ Total } \\
\hline & & $\mathrm{N}$ & $\%$ & $\mathrm{~N}$ & $\%$ & $\mathrm{~N}$ & $\%$ \\
\hline \multicolumn{2}{|c|}{ P0 } & 14 & 14 & 23 & 23 & 37 & 18.5 \\
\hline \multicolumn{2}{|c|}{ P1 } & 23 & 23 & 20 & 20 & 43 & 21.5 \\
\hline \multicolumn{2}{|c|}{$\mathrm{P} 2$} & 37 & 37 & 27 & 27 & 64 & 32 \\
\hline \multicolumn{2}{|c|}{ P3 } & 26 & 26 & 30 & 30 & 56 & 28 \\
\hline \multicolumn{2}{|c|}{ Total } & 100 & 100 & 100 & 100 & 200 & 100 \\
\hline \multirow{2}{*}{ Chi-square } & $\mathrm{X}^{2}$ & \multicolumn{6}{|c|}{4.247} \\
\hline & $\mathrm{P}$-value & \multicolumn{6}{|c|}{0.236} \\
\hline
\end{tabular}

Table (3): Comparison between the two groups as regard mode of delivery 


\begin{tabular}{|c|c|c|c|c|c|c|c|}
\hline \multirow{2}{*}{\multicolumn{2}{|c|}{ Mode of delivery }} & \multicolumn{2}{|c|}{ Group A } & \multicolumn{2}{|c|}{ Group B } & \multicolumn{2}{|c|}{ Total } \\
\hline & & $\mathrm{N}$ & $\%$ & $\mathrm{~N}$ & $\%$ & $\mathrm{~N}$ & $\%$ \\
\hline \multicolumn{2}{|c|}{ CS } & 47 & 47 & 40 & 40 & 87 & 43.5 \\
\hline \multicolumn{2}{|c|}{ NVD } & 53 & 53 & 60 & 60 & 113 & 56.5 \\
\hline \multicolumn{2}{|c|}{ Total } & 100 & 100 & 100 & 100 & 200 & 100 \\
\hline \multirow{2}{*}{ Chi-square } & $\mathrm{X}^{2}$ & \multicolumn{6}{|c|}{0.997} \\
\hline & P-value & \multicolumn{6}{|c|}{0.318} \\
\hline
\end{tabular}

Table (4): Comparison between the two groups as regard postpartum hemorrhage

\begin{tabular}{|c|c|c|c|c|c|c|}
\hline \multirow{2}{*}{ P.P.H } & \multicolumn{2}{|c|}{ Group A } & \multicolumn{2}{c|}{ Group B } & \multicolumn{2}{c|}{ Total } \\
\cline { 2 - 8 } & $\mathrm{N}$ & $\%$ & $\mathrm{~N}$ & $\%$ & $\mathrm{~N}$ & $\%$ \\
\hline No & 94 & 94 & 67 & 67 & 161 & 80.5 \\
\hline Yes & 6 & 6 & 33 & 33 & 39 & 19.5 \\
\hline Total & 100 & 100 & 100 & 100 & 200 & 100 \\
\hline \multirow{2}{*}{ Chi-square } & $\mathrm{X}^{2}$ & \multicolumn{6}{|c|}{23.220} \\
\cline { 2 - 7 } & P-value & \multicolumn{7}{|c|}{$<0.001 * *$} \\
\hline
\end{tabular}

Table (5): Comparison between the two groups as regard lactation

\begin{tabular}{|c|c|c|c|c|c|c|c|}
\hline \multirow{2}{*}{\multicolumn{2}{|c|}{ Lactation }} & \multicolumn{2}{|c|}{ Group A } & \multicolumn{2}{|c|}{ Group B } & \multicolumn{2}{|c|}{ Total } \\
\hline & & $\mathrm{N}$ & $\%$ & $\mathrm{~N}$ & $\%$ & $\mathrm{~N}$ & $\%$ \\
\hline \multicolumn{2}{|c|}{ Artificial } & 44 & 44 & 47 & 47 & 91 & 45.5 \\
\hline \multicolumn{2}{|c|}{ Normal } & 56 & 56 & 53 & 53 & 109 & 54.5 \\
\hline \multicolumn{2}{|c|}{ Total } & 100 & 100 & 100 & 100 & 200 & 100 \\
\hline \multirow{2}{*}{ Chi-square } & $\mathrm{X}^{2}$ & \multicolumn{6}{|c|}{0.181} \\
\hline & P-value & \multicolumn{6}{|c|}{0.670} \\
\hline
\end{tabular}

Table (6): Comparison between the two groups as regard gestational age

\begin{tabular}{|c|c|c|c|c|c|c|c|}
\hline \multirow{2}{*}{\multicolumn{2}{|c|}{ GA }} & \multicolumn{2}{|c|}{ Group A } & \multicolumn{2}{|c|}{ Group B } & \multicolumn{2}{|c|}{ Total } \\
\hline & & $\mathrm{N}$ & $\%$ & $\mathrm{~N}$ & $\%$ & $\mathrm{~N}$ & $\%$ \\
\hline \multicolumn{2}{|c|}{ Preterm } & 5 & 5 & 18 & 18 & 23 & 11.5 \\
\hline \multicolumn{2}{|c|}{ Full term } & 95 & 95 & 82 & 82 & 177 & 88.5 \\
\hline \multicolumn{2}{|c|}{ Total } & 100 & 100 & 100 & 100 & 200 & 100 \\
\hline \multirow{2}{*}{ Chi-square } & $\mathrm{X}^{2}$ & \multicolumn{6}{|c|}{8.303} \\
\hline & P-value & \multicolumn{6}{|c|}{$0.004 *$} \\
\hline
\end{tabular}

Table (7): Comparison between the two groups as regard weight of baby

\begin{tabular}{|c|c|c|c|c|c|c|}
\hline \multirow{2}{*}{ Weight of baby } & \multicolumn{2}{|c|}{ Group A } & \multicolumn{2}{c|}{ Group B } & \multicolumn{2}{c|}{ Total } \\
\cline { 2 - 7 } & $\mathrm{N}$ & $\%$ & $\mathrm{~N}$ & $\%$ & $\mathrm{~N}$ & $\%$ \\
\hline$<2.5 \mathrm{~kg}$ & 90 & 90 & 84 & 84 & 174 & 87 \\
\hline$>2.5 \mathrm{~kg}$ & 10 & 10 & 16 & 16 & 26 & 13 \\
\hline Total & 100 & 100 & 100 & 100 & 200 & 100 \\
\hline \multirow{2}{*}{ Chi-square } & $\mathrm{X}^{2}$ & \multicolumn{6}{|c|}{1.592} \\
\cline { 2 - 7 } & P-value & \multicolumn{6}{c|}{0.207} \\
\hline
\end{tabular}

Table (8): Comparison between pre and post in the two groups as regard hemoglobin

\begin{tabular}{|c|c|c|c|c|c|c|c|c|}
\hline \multirow{2}{*}{ Hemoglobin $(\mathrm{gm} / \mathrm{dl})$} & \multicolumn{3}{|c|}{ Group A } & \multicolumn{3}{|c|}{ Group B } & \multicolumn{2}{|c|}{ T-test } \\
\hline & Mean & \pm & $\mathrm{SD}$ & Mean & \pm & SD & $\mathrm{T}$ & P-value \\
\hline Pre treatment & 6.33 & \pm & 0.47 & 6.24 & \pm & 0.51 & 1.298 & 0.195 \\
\hline 4 weeks after treatment & 9.25 & \pm & 0.48 & 7.94 & \pm & 0.54 & 18.132 & $<0.001 * *$ \\
\hline \multicolumn{7}{|c|}{ Paired t-test } & & \\
\hline $\mathrm{T}$ & \multicolumn{3}{|c|}{43.466} & \multicolumn{3}{|c|}{22.887} & & \\
\hline P-value & \multicolumn{3}{|c|}{$<0.001 * *$} & \multicolumn{3}{|c|}{$<0.001 * *$} & & \\
\hline
\end{tabular}


Table (9): Comparison between pre and post in the two groups as regard MCV.

\begin{tabular}{|c|c|c|c|c|c|c|c|c|}
\hline \multirow{2}{*}{ MCV } & \multicolumn{3}{|c|}{ Group A } & \multicolumn{3}{|c|}{ Group B } & \multicolumn{2}{|c|}{ T-test } \\
\hline & Mean & \pm & $\mathrm{SD}$ & Mean & \pm & $\mathrm{SD}$ & $\mathrm{T}$ & $\mathrm{P}$-value \\
\hline Pre treatment & 70.13 & \pm & 5.95 & 68.83 & \pm & 6.77 & 1.442 & 0.150 \\
\hline 4 weeks after treatment & 79.70 & \pm & 5.73 & 71.20 & \pm & 7.15 & 9.277 & $<0.001 * *$ \\
\hline \multicolumn{7}{|c|}{ Paired t-test } & & \\
\hline $\mathrm{T}$ & \multicolumn{3}{|c|}{11.585} & \multicolumn{3}{|c|}{2.407} & & \\
\hline P-value & \multicolumn{3}{|c|}{$<0.001 * *$} & \multicolumn{3}{|c|}{$0.017 *$} & & \\
\hline
\end{tabular}

Table (10): Comparison between pre and post in the two groups as regard HCT

\begin{tabular}{|c|c|c|c|c|c|c|c|c|}
\hline \multirow{2}{*}{ HCT } & \multicolumn{3}{|c|}{ Group A } & \multicolumn{3}{|c|}{ Group B } & \multicolumn{2}{|c|}{ T-test } \\
\hline & Mean & \pm & SD & Mean & \pm & $\mathrm{SD}$ & $\mathrm{T}$ & P-value \\
\hline Pre treatment & 19.61 & \pm & 1.47 & 19.22 & \pm & 1.62 & 1.783 & 0.076 \\
\hline 4 weeks after treatment & 28.19 & \pm & 1.56 & 24.51 & \pm & 1.67 & 16.103 & $<0.001 * *$ \\
\hline \multicolumn{7}{|c|}{ Paired t-test } & & \\
\hline $\mathrm{T}$ & \multicolumn{3}{|c|}{40.028} & \multicolumn{3}{|c|}{22.737} & & \\
\hline P-value & \multicolumn{3}{|c|}{$<0.001 * *$} & \multicolumn{3}{|c|}{$<0.001 * *$} & & \\
\hline
\end{tabular}

Table (11): Comparison between pre and post in the two groups as regard MCHC

\begin{tabular}{|c|c|c|c|c|c|c|c|c|}
\hline \multirow{2}{*}{ МСНС } & \multicolumn{3}{|c|}{ Group A } & \multicolumn{3}{|c|}{ Group B } & \multicolumn{2}{|c|}{ T-test } \\
\hline & Mean & \pm & SD & Mean & \pm & $\mathrm{SD}$ & $\mathrm{t}$ & P-value \\
\hline Pre treatment & 21.10 & \pm & 4.86 & 20.43 & \pm & 5.10 & 0.951 & 0.342 \\
\hline 4 weeks after treatment & 26.07 & \pm & 4.79 & 23.07 & \pm & 5.36 & 4.173 & $<0.001 * *$ \\
\hline \multicolumn{7}{|c|}{ Paired t-test } & & \\
\hline $\mathrm{T}$ & \multicolumn{3}{|c|}{7.283} & \multicolumn{3}{|c|}{3.568} & & \\
\hline $\mathrm{P}$-value & \multicolumn{3}{|c|}{$<0.001 * *$} & \multicolumn{3}{|c|}{$<0.001 * *$} & & \\
\hline
\end{tabular}

Table (12): Comparison between pre and post in the two groups as regard Ferritin

\begin{tabular}{|c|c|c|c|c|c|c|c|c|}
\hline \multirow{2}{*}{ Ferritin } & \multicolumn{3}{|c|}{ Group A } & \multicolumn{3}{|c|}{ Group B } & \multicolumn{2}{|c|}{ T-test } \\
\hline & Mean & \pm & SD & Mean & \pm & $\mathrm{SD}$ & $\mathrm{t}$ & P-value \\
\hline Pre treatment & 22.23 & \pm & 4.30 & 21.27 & \pm & 4.91 & 1.471 & 0.142 \\
\hline 4 weeks after treatment & 38.37 & \pm & 5.62 & 28.50 & \pm & 4.67 & 13.507 & $<0.001 * *$ \\
\hline \multicolumn{7}{|c|}{ Paired t-test } & & \\
\hline $\mathrm{T}$ & \multicolumn{3}{|c|}{22.808} & \multicolumn{3}{|c|}{10.670} & & \\
\hline P-value & \multicolumn{3}{|c|}{$<0.001 * *$} & \multicolumn{3}{|c|}{$<0.001 * *$} & & \\
\hline
\end{tabular}

Table (13): Comparison between the two groups as regard myalgia, anaphylactic reaction and local thrombophlebitis

\begin{tabular}{|c|c|c|c|c|c|c|}
\hline & \multicolumn{2}{|c|}{ Group A } & \multicolumn{2}{c|}{ Group B } & \multicolumn{2}{c|}{ Chi-square } \\
\cline { 2 - 7 } & $\mathrm{N}$ & $\%$ & $\mathrm{~N}$ & $\%$ & $\mathrm{X}^{2}$ & P-value \\
\hline Myalgia & 1 & 1 & 0 & 0 & 1.005 & 0.316 \\
\hline Anaphylactic reaction & 0 & 0 & 1 & 1 & 1.005 & 0.316 \\
\hline Local thrombophlebitis & 1 & 1 & 0 & 0 & 1.005 & 0.316 \\
\hline
\end{tabular}

\section{DISCUSSION}

Iron deficiency is the most common cause of anemia in pregnancy. It accounts for $75-95 \%$ of cases of anemia in pregnancy ${ }^{(15)}$.

There is variation in hemoglobin levels during pregnancy; at the beginning of a pregnancy, there is a normal reduction in hemoglobin level followed by a slight increase towards the end of pregnancy. The initial reduction was explained to be a result from increased red cell mass and demands of the fetus which exceeds iron intake with consequent reduction in iron stores of the woman's body ${ }^{(16)}$.

Severe anemia is of particular concern as it poses a significant mortality and healthy risk. Pregnant women and young children are the 2 groups at highest risk. Severe anemia in 
pregnant women is associated with an elevated risk of perinatal and maternal mortality ${ }^{(17)}$.

Anemia during pregnancy is reported to have negative maternal and child health effect and elevated risk of perinatal and maternal mortality ${ }^{(\mathbf{1 8})}$.

Maternal anemia in pregnancy is commonly considered as risk factor for poor pregnancy outcome and can threaten the life of fetus and mother ${ }^{(19)}$. However, the extent to which the maternal hemoglobin concentration affects the fetal weight and fetal outcome is still uncertain. Some studies did not find a significant association between low hemoglobin before delivery and adverse outcome (20), while other studies showed a strong association ${ }^{(21)}$.

\section{I.V. Iron is most effective than I.M iron:}

This study proved that the intravenous iron therapy is more effective than the intramuscular iron therapy in treatment of severe anemia, according to these main results:

- Group A who received I.V iron, the Hb (pretherapy) was ranged from 5.5-7 $\mathrm{g} \%$, elevated to $8.5-10 \mathrm{~g} \%$, and the ferritin ranged from $14-29 \mathrm{ng} / \mathrm{ml}$, elevated to $31-48 \mathrm{ng} / \mathrm{ml}$.

- Group B who received I.M iron, the $\mathrm{Hb}$ (pretherapy) was ranged from 5.5-7 $\mathrm{g} \%$, elevated to $7-8.9 \mathrm{~g} \%$, and the ferritin ranged from $15-29 \mathrm{ng} / \mathrm{ml}$, elevated to $23-35 \mathrm{ng} / \mathrm{ml}$.

The results of this study are in agreement with those reported by Wali et al. ${ }^{(22)}$ who conducted a study to compare efficacy, safety and compliance of intravenous iron sucrose (group A), and intramuscular iron sorbitol (group B) in iron deficiency anemia in pregnancy.

The results reported by Wali et al. ${ }^{(22)}$ of mean $\mathrm{Hb}$ in group A was $8.9 \pm 0.7 \mathrm{~g} / \mathrm{dl}$ and in group B was $8.0 \pm 1.1 \mathrm{~g} / \mathrm{dl}$. After iron therapy, $\mathrm{Hb}$ showed an average elevation of $2.8 \mathrm{~g} / \mathrm{dl}$ in group A and $1.6 \mathrm{~g} / \mathrm{dl}$ in group B.

Another study reported by Singh et al. (23) found that mean pretherapy $\mathrm{Hb}$ in group $\mathrm{A}$ was $6.49 \mathrm{gm} / \mathrm{dl}$ and in group B was $6.48 \mathrm{gm} / \mathrm{dl}$. The increase in $\mathrm{Hb}$ after 4 weeks of therapy was $3.52 \mathrm{gm} / \mathrm{dl}$ in group A and $2.33 \mathrm{gm} / \mathrm{dl}$ in group B. The difference was statistically significant between group A (IV iron) and group B (IM iron).
The effect of iron deficiency anemia on maternal and fetal outcomes:

\section{1-Maternal outcome:}

A. The present study is in agreement with another study that was reported by Kavle et al. ${ }^{(24)}$ regarding the association between anemia during pregnancy and blood loss at and after delivery. The present study proved the positive relationship between the severity of anemia and the postpartum hemorrhage. Kavle et al. ${ }^{(24)}$ examined the relationship between total blood loss (milliliter of blood loss at childbirth and postpartum) and anemia. At 36 weeks pregnancy, it was found that if maternal was $\mathrm{Hb}>110 \mathrm{~g} / \mathrm{L}$, the blood loss would be $249 \mathrm{ml}$, while if maternal $\mathrm{Hb}$ was $<90 \mathrm{~g} / \mathrm{L}$, the blood loss would be $311 \mathrm{ml}$.

This study proved the explanation of Rush ${ }^{(25)}$ in that severe anemia may weaken uterine muscular strength or lower resistance to infectious diseases, contributing to postpartum hemorrhage and subsequent maternal mortality.

B. The present study proved that there was no relation between the severity of anemia and the process of lactation either normally or artificially. Famando and Viteri ${ }^{(26)}$ proved that there is no evidence that anemic mothers are less competent than their normal counterparts in the process of lactation.

\section{2- Fetal outcome:}

A. A study reported by Preeti et al. ${ }^{(27)}$ shows the relation between the severity of anemia, low birth weight, stillbirth and the preterm birth.

- In severe anemic mothers: preterm birth was $20.76 \%$, low birth weight was $25.6 \%$, and stillbirth was $9 \%$.

- In mild to moderate anemic mothers: preterm birth was $11.27 \%$, low birth weight was $11.4 \%$, and stillbirth was $4.3 \%$.

B. Another study reported by Kidanto Hussein et al. ${ }^{(28)}$ proved that the risk of preterm delivery increased significantly with severity of anemia 1.4, 1.4 and 4.1 for women with mild, moderate and severe anemia, compared with women with normal $\mathrm{Hb}$ levels. The corresponding risks for LBW were 1.2, 1.7 and 3.8 for mild, moderate and severe anemia respectively. 
There are some study limitations that should be acknowledged:

First, this trial was limited to pregnant women with gestational age above 12 weeks and less than 36 weeks, therefore pregnant women who were coming to antenatal clinic with severe anemia above gestational age 36 weeks were excluded. Second, the difference between the results of the current study and the previous studies may be due to the usage of other forms of iron preparation. Third, it is recommended to measure and compare the efficacy of I.V and I.M iron on the neonatal $\mathrm{Hb}$ in the future studies.

The most important recommendation from this study to pregnant women, is to follow up by regular routine antenatal care for prevention of most anemic related morbidity (maternal and fetal).

\section{CONCLUSION}

Intravenous iron infusion is preferred to multiple intramuscular doses since the risk of anaphylaxis is present with either route of therapy and because of the case of administering single intravenous therapy as opposed to multiple intramuscular injections. The response to parenteral iron appeared to be faster than that for oral iron because of the greater amount of iron made available for hemoglobin synthesis in the bone marrow.

\section{REFERENCES}

1. Stevens G, Finucane M, De-Regil L et al. (2013): Nutrition Impact Model Study group (Anaemia). Global, regional, and national trends in total and severe anaemia prevalence in children and pregnant and non-pregnant women. Lancet Global Health, 1:16-25.

2. Shill KB, Karmakar P, Kibria G et al. (2014): Prevalence of iron-deficiency anemia among university students in Noakhali region, Bangladesh. J Health Popul Nutr., 32:103-110.

3. Pavord S, Myers B, Robinson S et al. (2012): British Committee for Standards in Haematology . UK guidelines on the management of iron deficiency in pregnancy. Br J Haematol., 156(5):588600.

4. Haider BA, Olofin I, Wang M et al. (2013): Anaemia, prenatal iron use, and risk Of adverse pregnancy outcomes: systematic review and meta-analysis. BMJ., 21: f 3443.

5. Abbaspour N, Hurrell R, Kelishadi $\mathbf{R}$ (2014): Review on iron and its importance for human health. J Res Med Sci., 19:164174.

6. Orlandini C, Torricelli M, Spirito $\mathbf{N}$ et al. (2017): Maternal anemia effects during pregnancy on male and female fetuses: are there any differences? J Matern Fetal Neonatal Med., 30(14):1704-1708.

7. Murray-Kolb LE (2013): Iron and brain functions. Curr Opin Clin Nutr Metab Care, 16:703-707.

8. Gautam CS, Saha L, Sekhri K et al. (2008): Iron deficiency in pregnancy and the rationality of iron supplem ents prescribed during pregnancy. Medscape $\mathbf{J}$ Med., 10:283.

9. Bayoumeu F, Subiran-Buisset C, Baka NE (2002): Iron therapy in iron deficiency anemia in pregnancy: intravenous route versus oral route. Am J Obstet Gynecol., 186: 518-522.

10. Perewusny KG, Huck R, Huck A (2002): Parenteral iron-sucrose complex. $\mathrm{Br} \mathrm{J}$ Nutr., 88:3-10.

11. Kumpf VJ and Holland EG (1990): Parentral iron dextran therapy. Ann pharmacother., 24 (2): 162-166.

12. Bhandal A and Russell $C$ (2006): Intravenous versus oral iron therapy for postpartum anemia BJOG., 113-1248-52.

13. George $K$ (2013): Z-Track injection, June 12. http:// www. healthline. com/ healthslideshow/history-adhd-timeline.

14. https://pharm.reviews/images/statyi/british -national-formulary-2015.pdf

15. Halimi S (2011): Oral versus parentral iron therapy for correction of iron deficiency anemia in pregnancy, Gomal Journal of Medical Sciences, (9): 1.

16. Reveiz L, Gyte GM, Cuervo LG (2007): Treatment for iron deficiency anemia in pregnancy. https://www.ncbi.nlm.nih.gov/pubmed/ 17443522

17. Murray-Kolb LE and Beard JL (2009): Iron deficiency and child and maternal health. The American journal of clinical nutrition, 89(3):946-50. 
18. Mbule MA, Byaruhanga YB, Kabahenda M, Lubowa A (2013): Determinants of anaemia among pregnant women in rural Uganda. Rural and Remote Health, 13(2): 2259.

19. Gregory $P$ and Taslim SA (2001): Health Status of the Pakistani population: a health profile and comparison with the United States. https://www.ncbi.nlm.nih.gov/pubmed/ 11189831

20. Umber J,Yasmeen K, Razia N (2007): Relationship between maternal hemoglobin and perinatal outcome .Rawal Medical Journal,32(2):102-104.

21. Akhter S, Momen MA, Rahman MM, Parveen T and Karim RK (2010): Effect of maternal anemia on fetal outcome . Mymensingh medical journal, 19 (3):3918.

22. Wali A, Mushtaq A and Nilofer (2002): Comparative study-efficacy, safe and compliance of intravenous iron sucrose and intramuscular of sorbitol in iron deficiency anemia of pregnancy. J Pakistan $\mathrm{Me}$ Assoc.,52(9): 392-5.

23. Singh S, Mahalingam H, Singh PK (2013): Polymer-supported titanium dioxide photocatalysts for environmental remediation: A review. Applied Catalysis A: General, 462:178-95.

24. Kavle JA, Stoltzfus RJ, Witter F, Tielsch JM, Khalfan SS, Caulfield LE (2008): Association between anaemia during pregnancy and blood loss at and after delivery among women with vaginal births in Pemba Island, Zanzibar, Tanzania. Journal of health, population, and nutrition, 26(2):232.

25. Rush D (2000): Nutrition and maternal mortality in developing world. Am $\mathbf{J}$ din Nutr., 72: 2125-405.

26. Famando E and Viteri A(1994): The consequences of iron deficiency and anemia in pregnancy. In: Nutrient Regulation During Pregnancy, Lactation and Infant Growth. L. Alien, J. King and B. Lönnerdal. Eds. Plenum Press, New York. pp. 121 - 133.

27. Preeti J, Kural M, Tulika J (2013): Maternal and fetal outcome in cases of severe anaemia with pregnancy in rural setup. Int J Med Appl Sci., 2(3):318-3.

28. Kidanto Hussein L, Ingrid M, Gunilla $L$, Siriel M, Lennarth N (2009): Risks for preterm delivery and low birth weight are independently increased by severity of maternal anaemia. S Afr Med J., 99:98-102. 